rith convulsions, and dies in three days. One kidney is whe lungs are normal. The occipital sinuses are the only intracranial venous canals that are losded. The meninges are scarlet. The corebral substance is normal.

\&. A male child, of eighteen months, with large head and of squat figure, thus resembling other members of its family, with teeth pressing on the gum, is seized with ischuria renalis, and cedems of the penis. The urine continues diminished in amount for a fortnight. Convulsions occur, and are repeated at intervals for twelve days. A second attack of convulsions takes place sixty days from second attack of convulsions takes place sixty day commencethe date of the ischuria, and convulsive seizure. The second attack proves fatal in twelve days. The urinary secretion continues scanty throughout the whole course of the illness. The post mortem examination is typical of what is observed in death occurring by convulsions during teething.

In conclusion, I have to observe that I do not maintain that hidney disease is al ways attended or succeeded by convulsions. In 1852 I met with a case of renal apoplexy in an infant of three months that proved fatal in fire days, without convulsions.

I have just a word or two to say respecting treatment. I consider it to be of great importance to treat the kidney affection by leeches and sinapisms to the loins, in addition to the ordinary method employed, of a warm bath, with cold applications to the head. The internal remedies that answer best are the saline mixtures, together with calomel.

\section{CASE OF ULCERATED STOMACH, CAUSING DEATH BY BEING SUDDENLY DETACHED FROM ITS ADHESION TO THE PERITONEUM.}

By Winlay Coluyss, Esq., M.R.C.S., Chudleigh, Devon.

I w $A$ s requested by a friend to open the body of a female relative, who had died suddenly, under circumstances for which he could not satisfactorily account. I extract from my note-book the following particulars, which he gave me, and the process verbal of the autopsy.

“E. W., aged 21 , a very fine young woman, but inclined to be corpulent, with a florid complexion, robust, and of active habits, had occasionally complained of an acute pain in the left hypochondrium, after taking a full meal; but, as it never lasted an hour at a time, and as her digestion was good, nothing was prescribed for her but an occasional aperient pill. Being corpulent, she was accustomed to have her stays laced very tight, and to wear a broad band round her waist, which was also made excessively tight; and it was thought the pressure might have caused the pain. One morning, after having used great exertion dancing at a ball the night before, she ate a hearty breakfast, and quickly after walked out with some young friends. Suddenly, she was seized with very severe pain in her side, from which she said something was tearing a way ; she shrieked violently, became faint, and fell down in the street. She was immediately removed to the house of her relatives, which she had shortly before left. Efficient medical aid was instantly obtained; but, after suffering intense agony for three hours, she expired."

Autopsy, twelve hours after death. I opened the abdominal cavity. There did not appear to be any omentum, but merely a ragged sort of fringe along the greater curvature of the stomach. There was no external appearance of inflammation on the stomach or intestines; but on that portion of the lesser curvature of the stomach, which in the erect position of the body would have been in contact with the abdominal parietes on the left side, these was a considerable deposit of coagulable lymph, and a perforation into the stomach from internal ulceration. There was also a similar deposit of lymph on the membranous lining of the abdominal cavity, to which it was apparent the stomach had adhered; and it wes opposite this spot that she had always complained of the pain. The stomach was very large, and contained a good deal of undigested food; but the fluid parts had escaped into the carity. All the other abdominal viscera were perfectly sound.*

\section{CASE OF CIRSOID ANEURISM.}

By W. E. Crowfoor, Esq., F.R.C.S., Beccles, Suffolk. [Read beforc the Sufjolk Branch, June 20th, 1856.]

THE following case may prove interesting, as illustrating a disease of rare occurrence, of which the precise pathological character is not at present described, and for which no safe remedy has been suggested.

CASE. Charlotte Clarke, aged 23 years, a marricd woman, and the mother of two children, came under my care in May 1844. I took the following notes of her case at that time :-

She is fair, with a fresh and florid complexion, and states that she has suffered for many years from severe pain in the head. About eight months since, and two months previous to her last confinement, her pain became extremely aggravated, especially upon lying down; the sight in her right eye became dim, and is now almost entirely lost; both pupils are much dilated; she has a coustant noise in her ears, like the fall of rushing waters, becomes frequently delirious at night, and all her symptoms are much aggravated when the head is lowered, so that she is always obliged to sleep in a sitting posture; her health is in other respects good; the bowels are regular; the catamenia returued as usual after weaning, and the pulse is regular and natural in frequency.

At the age of eleven she first observed a slight swelling on the upper and right side of the forehead, just on the frontal protuberance; this gradually went on increasing, but without pain, till about three weeks since, when it became extremely scnsitive, and it now presents the following appearances. The right temporal artery, after passing in front of the ear, becomes extremely thin in its coats, and tortuous and varicose in its course; upon reaching the frontal protuberance, the original seat of the disease, it becomes dilated to the size of the little finger, and upon applying the ear to the swelling in that situation a distinct whizzing and bellows sound is to be heard, similar to that observed in an aneurism; the vessel continues in the same dilated and tortuous state to the extent of seven inches over the vertex, precisely resembling in appearance a varicose vein in the leg; it is exquisitely sensitive throughout its whole course; it is joined by numerous anastomosing branches from the supraorbital and frontal arteries of the right side, and by the left temporal. It has by pressure produced absorption of the external table of the frontal bone; so that it appears to run in a groove in that bone, the roughened edges of which may be distinctly felt. All the neighbouring vessels are extremely tender, as is also the right carotid throughout its whole course; the eye and circumference of the orbit on the right side are also very painful when pressed upon. The arrest of the circulation in the right temporal produces but little influence upon the tumour; but when the right carotid is compressed, the pulsation almost ceases in it, and does so entirely when both carotids are compressed, which, of course, can only be borne for a few seconds.

Such was the state of the disease as noted in 1844 ; since that time she has been three times confined, had very severe hæmorrhages on each occasion, and also loses very largely at each catamenial period, and has, at the same time, generally considerable hæmoptysis; she still suffers severely from her head, with occasional attacks of faintness; her sight is improved; she can lay with her head lower, and has less noise in her ears; the diseased vessels are themselves gradually becoming larger, but, on the whole, are less painful than formerly, and she discharges her house-

- I have the stomach in my possession, but hare lately found this note, which was made twenty.fire years ago.-W. C. 